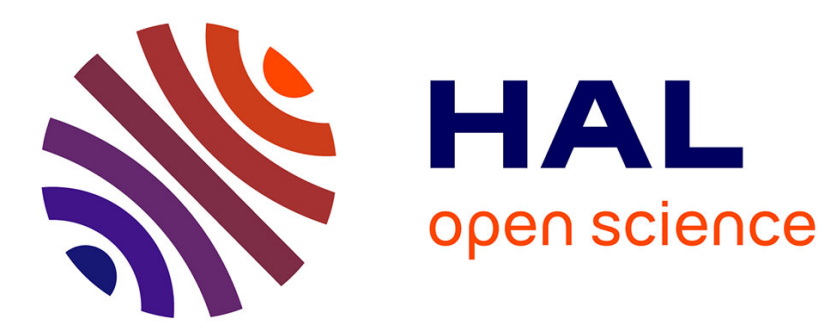

\title{
Mechanism of Elongation of Gold or Silver Nanoparticles in Silica by Irradiation with Swift Heavy Ions
}

K. Awazu, X. Wang, M. Fujimaki, J. Tominaga, S. Fujii, H. Aiba, Y. Ohki, T. Komatsubara

\section{- To cite this version:}

K. Awazu, X. Wang, M. Fujimaki, J. Tominaga, S. Fujii, et al.. Mechanism of Elongation of Gold or Silver Nanoparticles in Silica by Irradiation with Swift Heavy Ions. The Seventh International Symposium on Swift Heavy Ions in Matter, Jun 2008, Lyon, France. hal-00204949

\section{HAL Id: hal-00204949 \\ https://hal.science/hal-00204949}

Submitted on 22 Jul 2008

HAL is a multi-disciplinary open access archive for the deposit and dissemination of scientific research documents, whether they are published or not. The documents may come from teaching and research institutions in France or abroad, or from public or private research centers.
L'archive ouverte pluridisciplinaire HAL, est destinée au dépôt et à la diffusion de documents scientifiques de niveau recherche, publiés ou non, émanant des établissements d'enseignement et de recherche français ou étrangers, des laboratoires publics ou privés. 


\section{Mechanism of Elongation of Gold or Silver Nanoparticles in Silica by Irradiation with}

\section{Swift Heavy Ions}

Koichi Awazu ${ }^{1}$, Xiamin Wang ${ }^{1}$, Makoto Fujimaki ${ }^{1}$, Junji Tominaga ${ }^{1}$, Shinji Fujii ${ }^{2}$, Hirohiko Aiba $^{2}$, Yoshimichi.Ohki ${ }^{2}$, Tetsuro Komatsubara ${ }^{3}$

${ }^{1}$ CAN-FOR, National Institute of Advanced Science and Technology, 1-1-1 Higashi Tsukuba 305-8562, Japan; ${ }^{2}$ Waseda University Shinjuku, Tokyo 169-8555, Japan; ${ }^{3}$ Tandem Accelerator Complex, University of Tsukuba, Tsukuba 305-8577, Japan

Abstract

It has been reported that elongated Au nanoparticles oriented parallel to one another can be synthesized in $\mathrm{SiO}_{2}$ by ion irradiation. Our aim was to elucidate the mechanism of this elongation. We prepared $\mathrm{Au}$ and $\mathrm{Ag}$ nanoparticles with a diameter of $20 \mathrm{~nm}$ in an $\mathrm{SiO}_{2}$ matrix. It was found that Au nanoparticles showed greater elongated with a higher flux of ion beam and with thicker $\mathrm{SiO}_{2}$ films. In contrast, Ag nanoparticles split into two or more shorter 
nanorods aligned end to end in the direction parallel to the ion beam. These experimental results are discussed in the framework of a thermal spike model of Au and Ag nanorods embedded in $\mathrm{SiO}_{2}$. The lattice temperature exceeds the melting temperatures of $\mathrm{SiO}_{2}, \mathrm{Au}$ and Ag for 100 ns after one $110-{\mathrm{MeV} \mathrm{Br}^{10+}}^{10 n}$ has passed through the middle of an $\mathrm{Au}$ or $\mathrm{Ag}$ nanorod.

Author to whom correspondence should be addressed. Electronic mail: k.awazu@aist.go.jp PACS: 81.16.-c, 61.80.Jh, 62.20.Fe, 81.40.Lm, 68.60.Bs

Key words; swift heavy ion, nanofabrication, Au nanoparticles, silica glass

\section{Introduction}

Well-defined Au nanoparticles and nanorods are desirable for their optical properties. The size and shape of nanocrystals affect the position of the plasmon bands, which in turn have been widely used in surface enhanced spectroscopy that includes both Raman and fluorescence. Gold nanoparticles or nanorods can be deposited randomly on a substrate,[1] but it is difficult to synthesize Au nanorods that are oriented parallel to each other and perpendicular to the substrate.[2], [3] The goal of the experiment from the viewpoint of 
application to nanophotonics was to reveal new optical properties of Au nanorods. We also aimed to resolve the interesting phenomenon of elongation of Au nanoparticles in $\mathrm{SiO}_{2}$. To theoretically understand the mechanism of elongation, we employed the thermal spike model,[4] since it explains many phenomena caused by ion bombardment. However, several problems with thermal spike models have been pointed out.[5] For example, temperature changes in the order of femto-seconds cannot be defined. It is also impossible to ignore the pressure dependence of the different physical parameters of the lattice. Such questions remain controversial, so we will not focus on these matters in the present report.

\section{Experimental procedures}

A thermally oxidized silicon wafer was prepared as the $\mathrm{SiO}_{2}$ substrate. The thickness of the $\mathrm{SiO}_{2}$ layer on the silicon was $2 \mu \mathrm{m}$. Five-nm-thick $\mathrm{Au}$ or $\mathrm{Ag}$ films were deposited on the substrate by evaporation of high-purity Au or Ag grains. After deposition, both the thin Au and Ag films were heated at $300{ }^{\circ} \mathrm{C}$ for $10 \mathrm{~min}$ to form nanoparticles. The nanoparticles were then embedded in an $\mathrm{SiO}_{2}$ layer deposited by radio frequency magnetron sputtering of a silica 
target in an Ar atmosphere. The thickness of the top layer of $\mathrm{SiO}_{2}$ was set to $200 \mathrm{~nm}$ or $1 \mu \mathrm{m}$ by selecting deposition time. The direction of propagation of the ion beam was perpendicular to the upper surface of the $\mathrm{SiO}_{2}$. The 12-unit double-Pelletron tandem accelerator at the University of Tsukuba was used to irradiate the assemblies with $110-\mathrm{MeV} \mathrm{Br}^{10+}$ ions. Crosssections of the pristine and irradiated samples were examined by transmission electric microscopy (TEM) using a Hitachi H-9500 300-kV instrument. Specimens for TEM observation with a thickness of $100 \mathrm{~nm}$ were produced using a focused beam of $20-\mathrm{keV} \mathrm{Ga}^{+}$ ions from a Hitachi FB-2100 instrument.

The temperature evolutions of the particles when irradiated by swift heavy ions are simulated using the thermal spike model $[4,7,8]$. We extended this model to include two materials to accommodate the current particle case. First, the swift ion deposits its energy in the electron subsystem according to the radial distribution given by the Katz model [9]. The hot electrons then diffuse their energy by means of electron-electron scattering and electronphonon coupling. To simulate this heat-diffusing process numerically, we need to know all the thermal parameters. For the electron subsystems’ specific heats and thermal conductivities, we assumed constant values for the insulator $\mathrm{SiO}_{2}$ as given in [4] and temperature-dependent 
values for the metal Au and Ag as in [8]. For the lattice subsystems, we used the thermodynamic parameters of bulk materials as an approximation. $\mathrm{SiO}_{2}$ 's specific heat is fitted to the data given by $[10,11]$, and the specific heats of Au and Ag are from [12]. Their thermal conductivities are from the data recommended in Touloukian's handbook [13]. In addition, the electron-lattice coupling parameter of $\mathrm{SiO}_{2}$ is derived from the experimentally fitted mean energy diffusion length $\lambda$ given by [4]. The coupling parameter of silver is given theoretically by the quasi-free electron gas model [8].

3. Results and discussion

We examined the elongation of Au nanoparticles as a function of the thickness of $\mathrm{SiO}_{2}$ on Au nanoparticles and as a function of ion flux. Figures 1 show cross-sectional TEM views of Au nanoparticles generated at $300{ }^{\circ} \mathrm{C}$ and subsequently embedded in $\mathrm{SiO}_{2}$. The thicknesses of the $\mathrm{SiO}_{2}$ layer for Au nanoparticles in (a), (b) and (d) are $200 \mathrm{~nm}$ and for (c) it is $1 \mu \mathrm{m}$. Figure 1 (a) presents Au nanoparticles in $\mathrm{SiO}_{2}$ before irradiation. Particle size is estimated from the TEM view at $20 \mathrm{~nm}$. The Au particles in the pristine film seems to be touching each other in Figures 1 (a). But from plane view of scanning electronic microscope (SEM), we 
confirmed that Au particles were separated. Figures 1(b), (c) and (d) show Au nanoparticles embedded in $\mathrm{SiO}_{2}$ after irradiation with $110-\mathrm{MeV} \mathrm{Br}^{10+}$ ions at a fluence of $1 \times 10^{14} \mathrm{~cm}^{-2}$. Ion fluxes are $8 \pm 2 \times 10^{10} \mathrm{~cm}^{-2} \mathrm{sec}^{-1}$ for (b) and (c) and $1.5 \pm 0.2 \times 10^{11} \mathrm{~cm}^{-2} \mathrm{sec}^{-1}$ for (d). In the pictures, the direction of ion propagation is from top to bottom, as shown by the arrow. A comparison between (b) and (d) shows that Au nanoparticles under $1 \mu \mathrm{m}$ thick $\mathrm{SiO}_{2}$ were much more elongated than those under $200 \mathrm{~nm}$ thick $\mathrm{SiO}_{2}$. A comparison between (b) and (c) reveals that Au nanoparticles are much more elongated at higher ion fluxes.

Here we discuss the dependence of $\mathrm{SiO}_{2}$ thickness. Klaümunzer et al. proposed the effect of matrix hammering introduced the particles creep.[14] Penninkhof et al. have reported that in colloids consisting of a Au core and a silica shell, the Au core showed a large elongation along the ion beam direction, provided the silica shell is thick enough ( $>40 \mathrm{~nm})$. [15] Our present results are consistent with the report by Penninkhof et al.. The model proposed by them to explain the elongation of the Au core is an indirect deformation scenario in which the in-plane strain generated by ion tracks in the silica shell imposes a stress on the metal core. [15] With the Au being relatively soft under ion irradiation, this in-plane stress may then cause the Au core to flow in the out-of-plane direction, i.e. along the direction of the 
ion beam, by Newtonian viscous flow. [15] This argument seems consistent with the fact that larger elongation is found for colloids with a thicker silica shell. About the flux dependence, we assumed that at high flux they did not have the time to cool between successive impacts on the same area.

Silver nanoparticles embedded in $\mathrm{SiO}_{2}$ are shown in Figure 2 (a). The thickness of the top layer of $\mathrm{SiO}_{2}$ is $200 \mathrm{~nm}$. Ag nanoparticles of a uniform diameter of $20 \mathrm{~nm}$ are present in the $\mathrm{SiO}_{2}$. After irradiation with $110-\mathrm{MeV} \mathrm{Br}^{10+}$ ions at a fluence of $1 \times 10^{14} \mathrm{~cm}^{-2}$ and at a flux of $8 \pm 2 \times 10^{10} \mathrm{~cm}^{-2} \mathrm{sec}^{-1}$, Ag nanoparticles split into two or more shorter nanorods aligned end to end in the direction parallel to the ion beam.

Penninkhof et al. reported the behavior of Ag cores embedded in silica with $30 \mathrm{MeV} \mathrm{Si}$ ions irradiation and Ag cores did not show elongation. [15] The Ag behavior in the present work is different from the previous report.

Lattice temperature for $\mathrm{Au}$ and $\mathrm{Ag}$ nanorods with radii of $5 \mathrm{~nm}$ embedded in $\mathrm{SiO}_{2}$ were calculated and are shown in Figures 3 (a) and (b), respectively. Here we used nanorods, not nanoparticles because calculation of temperature on nanorods is simpler than that on nanoparticles and Au shape is close to nanorods after irradiation. These show the evolution of 
the lattice temperature against time at various distances from the ion axis. For a time of less than $10^{-13} \mathrm{~s}$, the temperature characterizes the energy imparted to the atoms. In Figure 3(a), the temperatures of the Au nanorod monitored at $1 \mathrm{~nm}$ and $3.5 \mathrm{~nm}$ from the center are shown by black squares and red circles, respectively. $300 \mathrm{fs}\left(3 \times 10^{-13} \mathrm{~s}\right)$ after the ion impact, both temperatures exceed the melting point of Au (1337 K), which is shown by a black dashed line. The maximum temperatures at both distances also reach the melting point of $\mathrm{SiO}_{2}(1992 \mathrm{~K})$, which is shown by a dashed horizontal line. A point $6.5 \mathrm{~nm}$ from center of an Au nanorod of radius $5 \mathrm{~nm}$ is located within the $\mathrm{SiO}_{2}$ matrix. The temperature there at this point increases dramatically 5 fs $\left(5 \times 10^{-15} \mathrm{~s}\right)$ after ion impact, and exceeds the melting point of $\mathrm{SiO}_{2}$ for a period between $20 \mathrm{fs}$ and $10 \mathrm{ps}$ after the ion impact. The lattice temperature $10 \mathrm{~nm}$ from the center of the nanoparticle does not exceed the melting point of $\mathrm{SiO}_{2}$. $\mathrm{SiO}_{2}$, as well as $\mathrm{Au}$, is melted for $10 \mathrm{ps}$ in the region within $10 \mathrm{~nm}$ of the center of the nanoparticle. In other words, the periphery of particles rather undergo an overheating with respect to the core because of the low thermal conductivity of the surrounding matrix.

Here we should explain why the silica temperature increases before that of the $\mathrm{Au}$ nanoparticle even though the incident ion energy is first deposited in the Au nanoparticle and 
only then coupled to the silica matrix. The electrons along the ion's path respond instantaneously to the penetrating ion, resulting in a rise in electronic temperature. These hot electrons within Au then diffuse their energy rapidly to electrons in the surrounding silica and cause their temperature to be raised correspondingly. Because the electron-lattice coupling constant of silica is greater than that of Au although its conductivity is smaller, we observed in the simulation that the silica lattice temperature increases ahead of the inner Au particle, and thus will feed the heat back to the particle by phonon-phonon interactions.

In the experiment, however, Au nanoparticles $10 \mathrm{~nm}$ in radius are elongated by irradiation from the experimental results as depicted in Figure 1. The radius in the experiments does not exactly match those obtained in the calculation, due to the inherent limitations of the current spike model as well as uncertainty of the input parameters.

We found from Figures 1 (b) and (d) that the elongation of Au nanoparticles depends on ion flux. This may imply that cooling time is not sufficient after initial ion bombardment at higher ion flux. It was found that Au nanoparticles are elongated but that Ag nanoparticles are split into two or more. Figures 3 (a) and (b) based on the thermal spike mode reveal no obvious difference in the lattice temperatures of $\mathrm{Au}$ and $\mathrm{Ag}$ nanoparticles in $\mathrm{SiO}_{2}$. 
Summary

In the present study, we found that the elongation of $\mathrm{Au}$ nanoparticles embedded in $\mathrm{SiO}_{2}$ was influenced by ion flux and $\mathrm{SiO}_{2}$ thickness. Silver nanoparticles are elongated and split into two or more under irradiation. We concluded that the elongation mechanisms must consist of combination of the particle creep under the effect of the matrix hammering, thermal spike, mechanical effects driven by stresses around the ion tracks.

Acknowledgement: This study was financially supported by the Budget for Nuclear Research of the Ministry of Education, Culture, Sports, Science, and Technology, based on screening and counseling by the Atomic Energy Commission. 


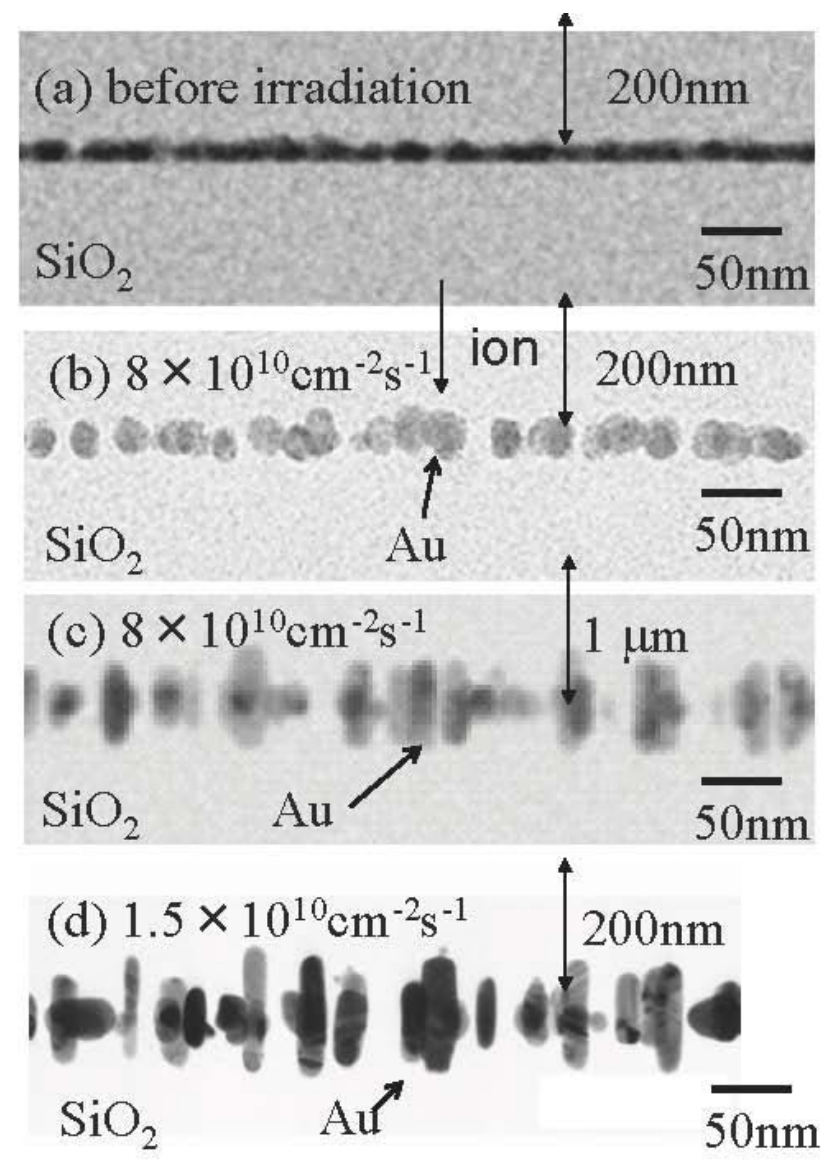

Figure 1 Cross-sectional TEM image of Au nanoparticles embedded in $\mathrm{SiO}_{2}$. (a), before ion irradiation. (b)-(d), irradiated with $110-\mathrm{MeV} \mathrm{Br}^{10^{+}}$at a fluence of $1 \times 10^{14} \mathrm{~cm}^{-2}$. Thicknesses of $\mathrm{SiO}_{2}$ are $200 \mathrm{~nm}$ [(a), (b), (d)] and $1 \mu \mathrm{m}$ (c). Ion fluxes are $8 \pm 2 \times 10^{10} \mathrm{~cm}^{-2} \mathrm{sec}^{-1}$ [(b), (c)] and $1.5 \pm 0.2 \times 10^{11} \mathrm{~cm}^{-2} \mathrm{sec}^{-1}(\mathrm{~d})$. 

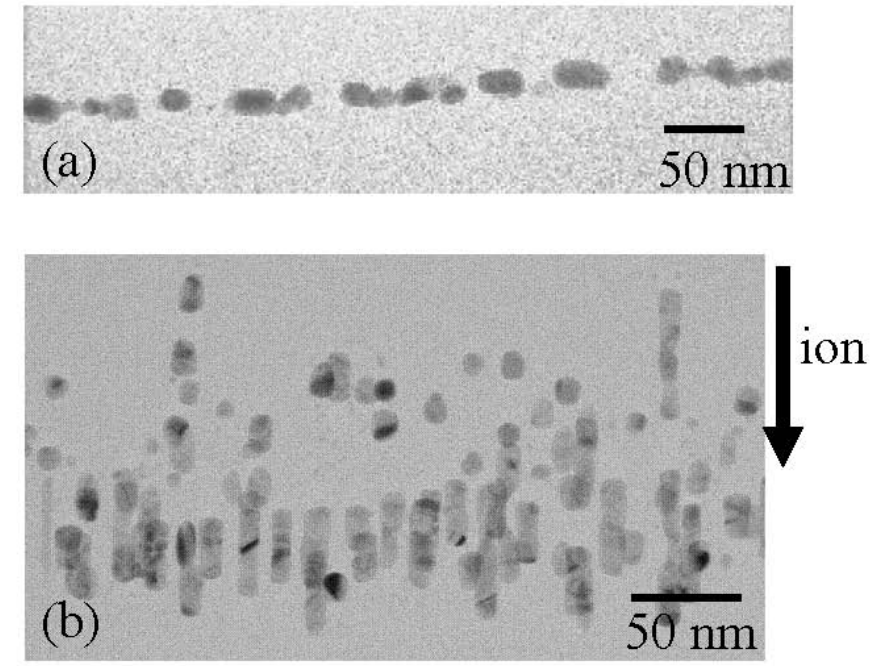

Figure 2 Cross-sectional TEM image of Ag nanoparticles embedded in $\mathrm{SiO}_{2}$. (a) followed by $110-\mathrm{MeV} \mathrm{Br}^{10+}$ ion bombardment at a fluence of $1 \times 10^{14} \mathrm{~cm}^{-2}$ and at a flux of $8 \pm 2 \times 10^{10}$ $\mathrm{cm}^{-2}$. 


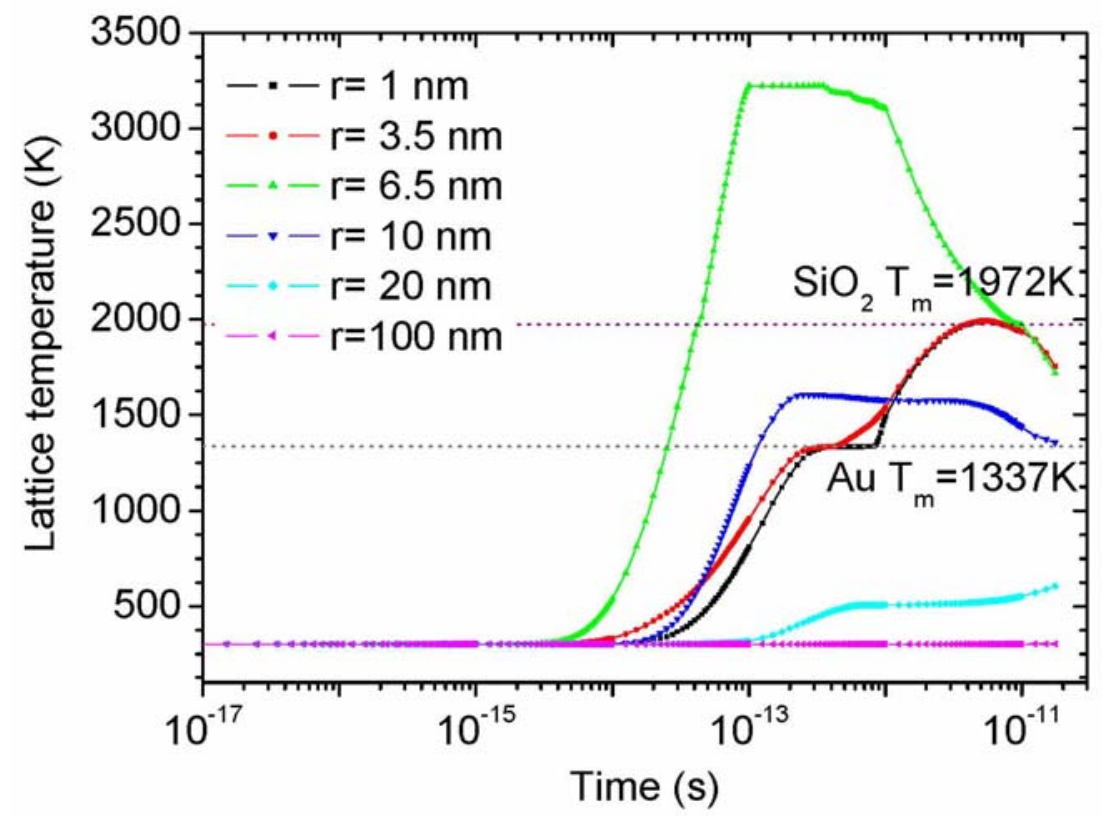

(a)

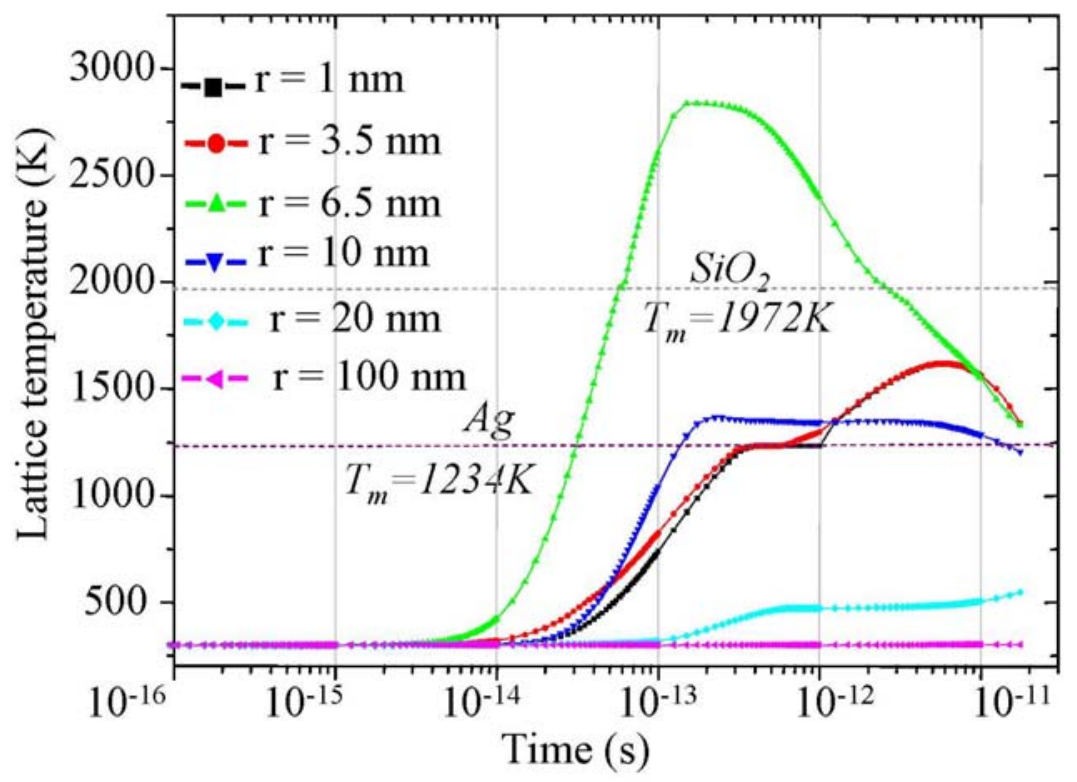

(b)

Figure 3 The calculated lattice temperature versus time at distances of 1, 3.5, 6.5, 10, 20, and $100 \mathrm{~nm}$ from the ion path. (a) and (b), 5-nm-radius Au and Ag nanoparticles embedded in $\mathrm{SiO}_{2}$, respectively. The sample is at $300 \mathrm{~K}$. The melting temperatures of $\mathrm{SiO}_{2}, \mathrm{Au}$ and $\mathrm{Ag}$ are shown in the Figures. 
Reference

[1] N. Halas, MRS Bull., 30 (2005) 362.

[2] S. Roorda, T. V. Dillen, A. Polman, C. Graf, A. V. Blaaderen and B. J. Kooi, Adv. Mater., $16(2004) 235$.

[3] Y. K. Mishra, D. K. Avasthi, P. K. Kulriya, F. Singh, D. Kabiraj, A. Tripathi, J. C. Pivin and I. S. Bayer, A. Biswas, Appl. Phys. Lett. 90 (2007) 073110.

[4] M. Toulemonde, E. Paumier, J.M. Costantini, Ch. Dufour, A. Meftah and F. Studer, Nucl. Instrum. and Methods, B116 (1996) 37.

[5] S. Klaumünzer, Matematisk-fysiske Meddelelser 52 (2006) 293.

[6] S. Eustis and M. A. El-Sayed, Chem. Soc. Rev., 35 (2006) 209.

[7] M. Toulemonde, C. Dufour, A. Meftah and E. Paumier, Nucl. Instrum. and Methods, B166 (2000) 903. 
[8] Z. G. Wang, C. Dufour, E. Paumier and M. Toulemonde, J. Phys.: Condens. Matter, 6 (1994) 6733.

[9] M. P. R. Waligorski, R. N. Hamm and R. Katz, Radiation Measurements, 11 (1986) 309.

[10] David R. Lide (Editor), CRC Handbook of Chemistry and Physics - A Ready-Reference Book of Chemical and Physical Data, 86th Edition (CRC Press, Boca Raton, 2006).

[11] R.H. Perry and D. W. Green, Perry's Chemical Engineers' Handbook, the sixth edition, McGraw-Hill Book (New York, 1984).

[12] HSC Chemistry for Windows, Ver. 5.1, ESM Software (2005).

[13] Y. S. Touloukian, R. W. Powell and C. Y. Ho, et al (ed), Thermophysical Properties of Matter, 1 (IFI/Pleum , New York , 1970) 132.

[14] S. Klaumünzer, C.L. Li, S. Löffler, M. Rammensee, G.Schumacher and H.C. Neitzer, Rad. Eff. and Def. Sol. 108 (1989) 131.

[15] J.J. Penninkhof, T.van Dillen, S. Roorda, C. Graf, A. van Blaaderen, A. M. Vredenberg and A. Polman, Nucl. Instr. and Met. in Phys. Res. B242 (2006) 523. 